\title{
High-Frequency Deep Brain Stimulation of the Nucleus Accumbens Region Suppresses Neuronal Activity and Selectively Modulates Afferent Drive in Rat Orbitofrontal Cortex In Vivo
}

\author{
Clinton B. McCracken and Anthony A. Grace \\ Departments of Neuroscience, Psychiatry, and Psychology, University of Pittsburgh, Pittsburgh, Pennsylvania 15260
}

\begin{abstract}
High-frequency deep-brain stimulation (DBS) of the nucleus accumbens (NAc) region is an effective therapeutic avenue for patients with treatment-resistant obsessive- compulsive disorder (OCD). Imaging studies suggest that DBS acts by suppressing the aberrant metabolism in the orbitofrontal cortex (OFC) that is a hallmark of OCD; however, little is known about the mechanisms by which this occurs. We examined the effects of $30 \mathrm{~min}$ NAc DBS at $130 \mathrm{~Hz}$ on spontaneously active OFC neurons and local field potentials (LFPs) in addition to evoked responses elicited by single-pulse stimulation of the NAc or mediodorsal thalamus (MD) in urethane-anesthetized rats. NAc DBS reduced the mean firing rate of OFC neurons, although neurons receiving monosynaptic input from MD were less affected and some putative interneurons were excited by DBS. Single-pulse stimulation of the NAc produced a robust inhibition in OFC neurons that was attenuated after DBS, whereas excitatory responses were unchanged. In contrast, after DBS inhibitory responses evoked from MD were unchanged, whereas excitatory responses were enhanced. NAc-evoked LFP responses were potentiated after DBS, whereas MD-evoked LFP responses were unchanged. NAc DBS also enhanced OFC spontaneous LFP oscillatory activity in the slow $(0.5-4 \mathrm{~Hz})$ frequency band. These results suggest that DBS of the NAc region may alleviate OCD symptoms by reducing activity in subsets of OFC neurons, potentially by driving recurrent inhibition though antidromic activation of corticostriatal axon collaterals. Moreover, selective potentiation of input to these inhibitory circuits may also contribute to the therapeutic effects produced by DBS in OCD patients.
\end{abstract}

Key words: electrical stimulation; nucleus accumbens; prefrontal; thalamus; electrophysiology; obsessive-compulsive

\section{Introduction}

High-frequency (HF) electrical stimulation of specific subcortical structures, known as deep-brain stimulation (DBS), has attracted substantial attention for treatment of severe neurological and psychiatric disorders that fail to respond to pharmacotherapeutic intervention. Thus, DBS of thalamic and subthalamic nuclei is a relatively safe and efficacious alternative to ablative neurosurgery for Parkinson's disease and other movement disorders (Benabid et al., 1991, 1994; Krack et al., 2003; Rehncrona et al., 2003; Rodriguez-Oroz et al., 2005; Deuschl et al., 2006; Perlmutter and Mink, 2006). More recently, DBS of the ventral anterior internal capsule and ventral striatum has proven to be an effective therapeutic approach for treatment-resistant obsessive-compulsive disorder (OCD) (Nuttin et al., 1999; Anderson and Ahmed, 2003; Gabriels et al., 2003; Nuttin et al., 2003; Sturm et al., 2003;

Received June 26, 2007; revised Sept. 21, 2007; accepted Sept. 22, 2007

This work was supported by National Institutes of Health Grants MH57440, DA15408, and MH45156 (A.A.G.) and a by National Alliance for Research on Schizophrenia and Depression Young Investigator Award (C.B.M.). We thank N. Macmurdo and C. Smolak for technical assistance, B. Lowry for data acquisition software, and W. Lipski for assistance with MATLAB.

Correspondence should be addressed to Dr. Clinton B. McCracken, Department of Neuroscience, A210 Langley Hall, University of Pittsburgh, Pittsburgh, PA 15260. E-mail: cbm12@pitt.edu.

DOI:10.1523/JNEUROSCI.3750-07.2007

Copyright $\odot 2007$ Society for Neuroscience $\quad$ 0270-6474/07/2712601-10\$15.00/0
Abelson et al., 2005; Aouizerate et al., 2005; Greenberg et al., 2006). However, the neuronal mechanisms underlying the therapeutic actions of DBS in OCD remain unclear.

Imaging studies have provided insight into the brain systems involved in OCD and its treatment. Metabolic hyperactivity in the striatum, medial thalamus, and, in particular, the orbitofrontal cortex (OFC) has been consistently associated with OCD patients at rest (Baxter et al., 1988; Swedo et al., 1989) and is accentuated after symptom provocation (McGuire et al., 1994; Rauch et al., 1994; Breiter et al., 1996). Moreover, successful pharmacological (Swedo et al., 1992), cognitive-behavioral (Schwartz et al., 1996), and neurosurgical (Mindus et al., 1986) treatment of OCD have all been associated with reductions in activity in these same regions. Significantly, studies using DBS for OCD have also shown that successful treatment correlates with lowered activity in frontal cortical regions (Nuttin et al., 2003; Abelson et al., 2005; Van Laere et al., 2006).

The cellular mechanisms by which DBS produces therapeutic effects in OCD are not known. Drawing from the Parkinson's disease and movement disorders literature, DBS is proposed to act by decreasing neuronal activity within the stimulated nucleus, which is postulated to occur either by depolarization blockade or increase in local GABAergic transmission (Boraud et al., 1996; Benazzouz et al., 2000; Dostrovsky et al., 2000; Beurrier et al., 
2001; Kiss et al., 2002; Magarinos-Ascone et al., 2002; Lian et al., 2003). However, given that electrical stimulation preferentially activates axons as opposed to cell bodies (Nowak and Bullier, 1998a,b; McIntyre and Grill, 1999), it has been proposed that DBS may produce inhibition of the stimulated area but activation of efferent and afferent axons (Vitek, 2002; McIntyre et al., 2004a,b). Thus, characterizing the effects of HF stimulation on nuclei upstream and downstream from the stimulation site is necessary for clarifying the system-level actions of DBS. The purpose of the present study was to investigate the effects of HF electrical stimulation of the nucleus accumbens (NAc) region on spontaneous and evoked neuronal and local field potential (LFP) activity in the OFC in vivo.

\section{Materials and Methods}

Animals and surgery. Male Sprague Dawley rats (275-400 g) were anesthetized with urethane $(1.5 \mathrm{~g} / \mathrm{kg}$, i.p.) and placed in a stereotaxic frame. Body temperature was maintained at $37^{\circ} \mathrm{C}$ with a temperaturecontrolled heating pad. In all surgical preparations, the scalp was exposed, and burr holes were drilled in the skull overlying the lateral OFC, the NAc core, and the mediodorsal thalamus (MD). Concentric bipolar stimulating electrodes (NEX-100; David Kopf Instruments, Tujunga, $\mathrm{CA})$ were placed according to the following coordinates: NAc electrode: anteroposterior (AP), $+1.2 \mathrm{~mm}$ (from bregma); mediolateral (ML), $+2.0 \mathrm{~mm}$; dorsoventral (DV), $-6.9 \mathrm{~mm}$ (from skull); MD electrode: AP, $-3.2 \mathrm{~mm}$; ML, $+0.7 \mathrm{~mm}$; DV,$-5.5 \mathrm{~mm}$. All procedures were performed in accordance with the guidelines outlined in the National Institutes of Health Guide for the Care and Use of Laboratory Animals and were approved by the Institutional Animal Care and Use Committee of the University of Pittsburgh.

Single-unit recordings. Extracellular recording microelectrodes were constructed from borosilicate glass tubing using a vertical microelectrode puller (Narishige, Tokyo, Japan), with the tip broken back under microscopic control and filled with $2 \%$ pontamine sky blue dye dissolved in $2 \mathrm{M} \mathrm{NaCl}$ (impedance measured in situ ranged between 6 and $14 \mathrm{M} \Omega$ ). A burr hole was drilled over the OFC, the dura was resected, and a recording electrode was lowered slowly into the $\mathrm{OFC}(\mathrm{AP},+3.2 \mathrm{~mm}$; $\mathrm{ML}$, $+3.5 \mathrm{~mm}$; DV , 4.7-6.2 mm from skull) using a hydraulic micromanipulator. Signals from the recording electrode were amplified by a head stage connected to a preamplifier before being amplified and filtered $(0.05-16 \mathrm{kHz})$ by a window discriminator/amplifier unit (Fintronics, Orange, CT). Signals were also sent to an audio monitor (AM8; Grass Instruments, Quincy, MA) and displayed on an oscilloscope (Tektronics, Wilsonville, OR). The data were acquired, stored, and analyzed using custom-designed computer software (Neuroscope) with a data acquisition board interface (Microstar Laboratories, Bellevue, WA).

To identify OFC neurons responsive to single-pulse stimulation of the NAc or MD electrode, the microelectrode was lowered slowly through the OFC while stimuli were delivered alternately to the NAc and MD electrodes $(1000 \mu \mathrm{A})$ at $2 \mathrm{~s}$ intervals (i.e., each area was stimulated at 0.25 $\mathrm{Hz}$ ). Cathodal constant current pulses ( $0.2 \mathrm{~ms}$ duration) were given using a Grass Instruments S88 stimulator and a Grass Instruments photoelectric stimulus isolation unit. When a responsive neuron was identified, $5 \mathrm{~min}$ of baseline activity were recorded, after which peristimulus time histograms were constructed for 50 stimulations from each electrode. Two seconds of data were collected before and after the stimulus for each stimulus "sweep." Both inhibitory and excitatory responses were observed. Single-pulse stimulation of the NAc electrode frequently resulted in antidromic spikes recorded in OFC; however, because our aim in this study was to characterize the effects of DBS on spontaneous activity, the responses of antidromically activated OFC neurons to NAc DBS were not examined because of potential confounds as a consequence of this activation. Responsive neurons were classified as either putative pyramidal neurons or putative projection neurons based on the spike duration frequency histogram constructed from all OFC neurons recorded. Spike duration has proven to be a reliable measure for classifying neuron types in the frontal cortex in vivo (Tierney et al., 2004; Tseng et al., 2006).
In this study, neurons with spike durations of $<0.9$ ms were classified as putative interneurons, and neurons with spike durations $>1.1 \mathrm{~ms}$ were classified as putative pyramidal neurons.

Inhibitory responses before and after DBS were characterized according to the following: (1) the latency until inhibition onset; (2) duration of inhibition; and (3) changes in the magnitude of inhibition after DBS. The change in magnitude of inhibition after DBS was evaluated in two ways: (1) for a raw measure, the number of spikes discharged in the first $200 \mathrm{~ms}$ after stimulus was determined; and (2) for a normalized measure, the average percentage of baseline firing in the first $200 \mathrm{~ms}$ was calculated using 25 ms bins.

Excitatory responses were considered monosynaptic and presumed orthodromic if the response occurred within $15 \mathrm{~ms}$ of the stimulus, displayed spike "jitter" of at least $2 \mathrm{~ms}$ and a shift in spike latency with increasing current amplitude, and failed to follow $400 \mathrm{~Hz}$ paired-pulse stimulation (otherwise characterized as antidromic). Excitation was also quantified using complementary measures, including calculation of spike probability (i.e., the percentage of stimulations that result in an evoked spike), the number of spikes occurring within the first $25 \mathrm{~ms}$ after stimulus, and the percentage of baseline firing in the first $25 \mathrm{~ms}$ when calculated using $25 \mathrm{~ms}$ bins. With regard to $\mathrm{MD}$-evoked responses, it has been suggested that some longer-latency excitatory responses in the prefrontal cortex (PFC) may represent antidromic activation of corticothalamic afferents that invades local PFC recurrent collaterals (Pirot et al., 1994). Because the OFC has reciprocal connections with MD in a manner analogous to the medial PFC (mPFC) (Krettek and Price, 1977; Groenewegen, 1988), latencies longer than $15 \mathrm{~ms}$ for $\mathrm{MD} \rightarrow$ OFC excitatory responses were not included in the analysis to rule out this class of response (Pirot et al., 1994).

After recording evoked activity under baseline conditions, neurons were allowed to equilibrate for 3-5 min. An additional $5 \mathrm{~min}$ of baseline activity was then collected before recording with DBS-on for $30 \mathrm{~min}$. The DBS parameters used $(0.1-0.4 \mathrm{~mA}, 100 \mu \mathrm{S}$ pulse duration, $130 \mathrm{~Hz})$ have been shown to be efficacious in rat Parkinson's models (Chang et al., 2003; Degos et al., 2005) and are reported to cause negligible trauma to the stimulated area. This DBS protocol produced no visible lesions in the NAc under $25 \times$ light microscopy with cresyl violet staining. After $30 \mathrm{~min}$ of recording with DBS-on, baseline activity was recorded for an additional $5 \mathrm{~min}$, after which evoked activity was reassessed.

LFPs. When filter settings were adjusted to allow preferential passage of low-frequency (LF) signals (i.e., $0.1-1000 \mathrm{~Hz}$ ), single-pulse stimulation of either the NAc or MD resulted in large-amplitude LFP responses in the OFC. To determine the relative contributions of GABA and glutamate to these evoked LFP responses, evoked LFPs were recorded using a chemotrode (Plastics One, Roanoke, VA) that also allowed local infusion of drugs. The chemotrode consisted of two individually polyimideinsulated stainless steel wires $(0.2 \mathrm{~mm}$ diameter $)$ attached to an insulated stainless steel 26 gauge guide cannula. The wires extended $1 \mathrm{~mm}$ past the end of the guide cannula; when inserted, the tip of the injection cannula used was flush with the recording surface of the electrode. LFP responses were assessed after infusion of the $\mathrm{GABA}_{\mathrm{A}}$ receptor antagonist (-)bicuculline methiodide or the broad-spectrum ionotropic glutamate receptor antagonist kynurenic acid. Drugs or vehicle [Dulbecco's PBS (DPBS); Sigma, St. Louis, MO) were administered over 2 min using a 30 gauge injection cannula connected to a Hamilton syringe (bicuculline, $0.2 \mu \mathrm{g}$ in $0.5 \mu \mathrm{l}$ of DPBS; kynurenic acid, $10 \mu \mathrm{g}$ in $0.5 \mu \mathrm{l}$ of DPBS; vehicle, $0.5 \mu \mathrm{l}$ of DPBS). In a separate set of animals, using low-impedance glass microelectrodes (1-4 M $\Omega$ ), baseline input-output curves were constructed for these responses $(0.2-1.0 \mathrm{~mA}, 10$ stimulations at each current intensity, stimulation at $0.4 \mathrm{~Hz}$ ), then reassessed 5 and $90 \mathrm{~min}$ after $\mathrm{HF}$ $(130 \mathrm{~Hz})$ or LF $(10 \mathrm{~Hz})$ DBS. Spontaneous LFP activity was recorded immediately before and after 30 min DBS and occasionally during the first $5 \mathrm{~min}$ and last $5 \mathrm{~min}$ of DBS-on. We also examined the effects of the NMDA receptor antagonist (+)-5-methyl-10,11-dihydro-5H-dibenzo [a,d] cyclohepten-5,10-imine maleate (MK-801) on evoked LFPs before and after DBS. MK-801 (Sigma) was dissolved in vehicle (DPBS) and administered intraperitoneally.

Data analysis. Data are presented as mean \pm SEM. Spontaneous unit activity was assessed in terms of firing rate and the proportion of spikes 

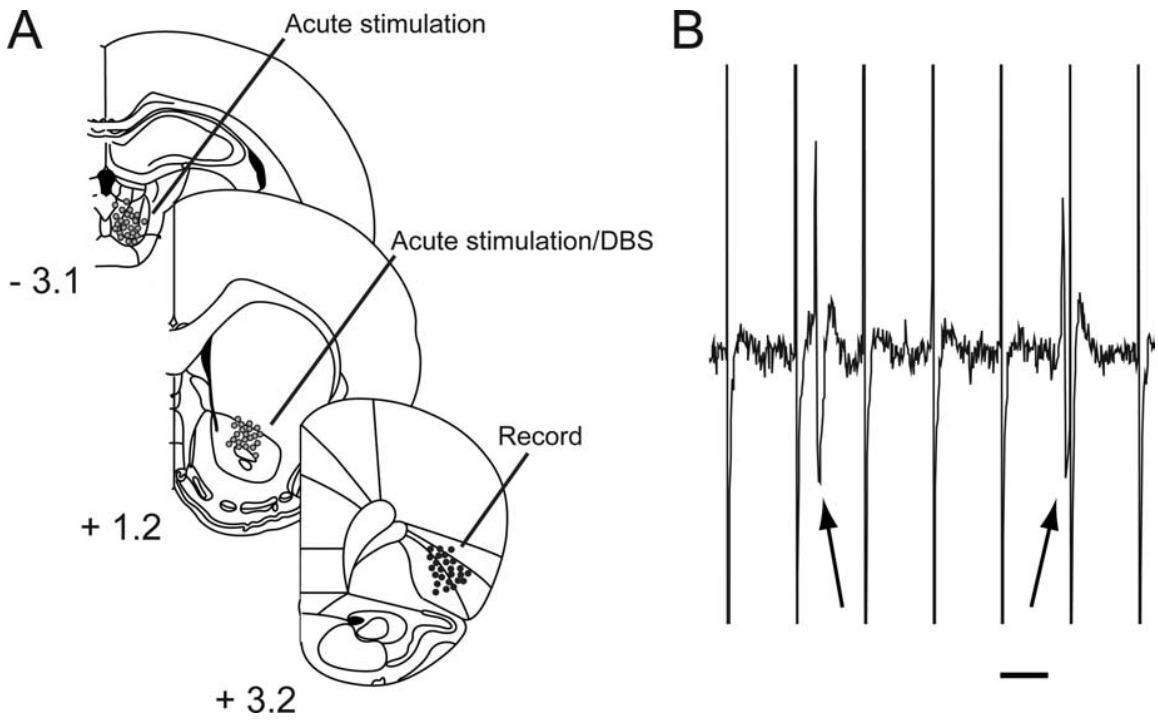

Figure 1. $A$, Recording sites in the OFC and stimulation sites in NAc and MD. For clarity, only representative nonoverlapping samples are shown. Numbers represent anterior/posterior distance from bregma. $\boldsymbol{B}$, Raw trace of neuronal firing with DBS-on. Arrows indicate spikes. Note that the spike on the right can be effectively discriminated both before and after the stimulus artifact. Calibration, $5 \mathrm{~ms}$.

fired in a bursting pattern. Bursts were defined as the occurrence of two spikes with an interspike interval (ISI) of $<45 \mathrm{~ms}$; this value was generated by fitting the ISI histogram of PFC neurons with the sum of two inverse Gaussian probability density functions as described previously (Laviolette et al., 2005).

For analysis of spontaneous LFP spectral density, LFP signals were filtered with a high cutoff of $100 \mathrm{~Hz}$, and fast Fourier transform-based periodograms were generated using 2 min of recorded LFP activity. The power spectral density data were binned into the following discrete frequency bands for analysis: slow/delta $(0.5-4 \mathrm{~Hz})$, theta $(4-12 \mathrm{~Hz})$, beta $(15-30 \mathrm{~Hz})$, and gamma $(35-80 \mathrm{~Hz})$. Values for each frequency band were also normalized to total power (to $100 \mathrm{~Hz}$ ). To assess LFP effects over time, spectral time-frequency plots were constructed using a continuous wavelet transform with a Morlet wavelet (wave number, 8) with the AutoSignal software platform (SysStat, San Jose CA)

Histology. At the end of each experiment, the recording site in the OFC was marked via electrophoretic ejection of pontamine sky blue dye from the tip of the recording electrode. Stimulation sites were marked by passing direct current through the stimulating electrode. After dye ejection, animals were decapitated, and brains were rapidly removed and fixed in formalin containing $0.1 \%$ potassium ferricyanide (to stain for stimulating electrode deposits) for a minimum of $24 \mathrm{~h}$. Brains were then sectioned into $50 \mu \mathrm{m}$ coronal slices and stained with cresyl violet to determine recording and stimulation sites (Fig. 1). In a subset of animals, the NAc stimulating electrode was not marked at the end of the experiment to evaluate the presence and extent of tissue damage produced by the DBS stimulation protocol.

Statistics. Spontaneous neuronal activity data collected during DBS was grouped into $5 \mathrm{~min}$ bins and analyzed by one-way repeatedmeasures ANOVA with the Student-Newman-Kewls post hoc test. Comparisons of pre- and post-DBS measures of evoked inhibition and excitation were performed using paired $t$ tests. Data that failed normality or equal variance testing were analyzed using the appropriate nonparametric tests (repeated-measures ANOVA for ranks, Wilcoxon signed-rank test). All analyses were performed using the SigmaStat software platform (SysStat)

\section{Results}

Spontaneous activity was sampled from 86 OFC neurons from 47 rats. The average firing rate of these neurons was $2.6 \pm 0.4 \mathrm{~Hz}$ (mean $\pm \mathrm{SEM})$. A total of 30 neurons responsive to single-pulse stimulation of the NAC were recorded for the duration of the
DBS experiment. Pure inhibitory responses were seen in $80 \%$ (23 of 30) of neurons; one neuron showed a shortlatency $(<15 \mathrm{~ms})$ excitatory response only, and six neurons showed shortlatency excitation followed by inhibition. The average latency of the short-latency excitatory responses was $8.3 \pm 1.1 \mathrm{~ms}$. Of the neurons showing excitation to acute NAc stimulation, $57 \%$ (four of seven) were putative interneurons based on spike duration. Many NAc-responsive neurons $(77 \% ; 23$ of 30$)$ also responded to $\mathrm{MD}$ stimulation. These neurons responded to MD stimulation with inhibition only (43\%; 10 of 23$)$, short-latency excitation only ( $27 \%$; 6 of 23$)$, or excitation followed by inhibition ( $30 \% ; 7$ of 23 ). The average latency of the excitatory responses was $9.8 \pm 1.0 \mathrm{~ms}$, which is consistent with a monosynaptic innervation of OFC based on analogous studies of thalamocortical latencies in the mPFC (Floresco and Grace, 2003). Of the neurons showing excitation to acute MD stimulation, 38\% (5 of 13) were putative interneurons. Three putative interneurons were excited by stimulation of both NAc and MD. A number of NAc-responsive cells showed excitatory responses to MD stimulation at latencies of 15-25 ms. Given the long latency of the excitatory response, these neurons were not considered to be monosynaptically driven by thalamocortical fibers but instead may have been activated via antidromic activation of local recurrent collaterals from corticothalamic fibers (Pirot et al., 1994; Floresco and Grace, 2003).

\section{Effects of DBS on spontaneous OFC neuronal firing}

The effect of NAc DBS on OFC neuron firing was examined by recording $5 \mathrm{~min}$ of baseline activity, followed by $30 \mathrm{~min}$ with DBS-on, followed by another $5 \mathrm{~min}$ with DBS-off (Fig. 2). In the first 5 min of stimulation, $57 \%$ (17 of 30) of neurons were inhibited ( $>25 \%$ decrease from baseline), 17\% (5 of 30) were excited ( $>25 \%$ increase from baseline), whereas $27 \%$ ( 8 of 30 ) were relatively unaffected. A subset (30\%; 9 of 30 ) of the neurons showed a complete or almost complete cessation of firing in the first few minutes of DBS. However, these initial effects were often transient and did not reflect the firing rate across the entire $30 \mathrm{~min}$ DBS (Fig. 2A1). Firing rate data were analyzed by grouping into 5 min bins for analysis across the DBS period. The mean firing rate of OFC neurons was significantly suppressed during the period of DBS $\left(\chi^{2}=24.15\right.$; df $\left.=7 ; p<0.001\right)$ (Fig. $\left.2 A\right)$. Differential effects of NAc DBS were seen when cells were classified as putative interneurons and principal neurons according to spike duration, such that putative pyramidal neurons $(n=20)$ were significantly inhibited by DBS ( $\chi^{2}=19.08$; df $\left.=7 ; p<0.01\right)$ (Fig. $2 B$ ), whereas the mean firing rate of putative interneurons $(n=7)$ was not affected by NAc DBS ( $\chi^{2}=13.19$; df $=7$; NS) (Fig. $2 B$ ). However, $75 \%$ (three of four) of putative interneurons that were driven by acute NAc stimulation showed initial excitatory responses to DBS. Neurons that received monosynaptic excitatory MD input $(n=13)$ were also relatively unaffected by DBS $\left(\chi^{2}=\right.$ 9.55; $\mathrm{df}=7$; NS) (Fig. 2C) compared with neurons that did not receive MD input [i.e., all other cells, $n=17\left(\chi^{2}=16.90\right.$; $\mathrm{df}=7$; $p<0.05$ )] (Fig. 2C). It should be noted that four of seven putative 
interneurons also were driven by MD. NAc DBS produced no significant changes in the percentage of spikes fired in bursts in any OFC neuronal subpopulation (data not shown).

\section{Evoked unit activity}

\section{Inhibition}

We examined the responses of OFC neurons to single-pulse stimulation of the NAc and MD before and after DBS (Fig. 3). Almost all neurons recorded (29 of 30) responded to NAc stimulation with an inhibition of firing, with five of these neurons showing a short-latency excitation followed by inhibition. The mean onset of inhibition by NAc stimulation was not different before and after DBS (26.0 \pm 6.7 vs $31.9 \pm 6.2 \mathrm{~ms}$; NS) (Fig. $3 A$ ), whereas the mean duration of inhibition was significantly reduced after DBS $(258.7 \pm 24.5$ vs $154.0 \pm 15.5 \mathrm{~ms} ; p<0.05)$. The magnitude of inhibition was also significantly reduced after DBS, when measured both by the mean total number of spikes in the first $200 \mathrm{~ms}$ after stimulus $(6.6 \pm 2.1$ vs $11.2 \pm$ 3.3 spikes; $p<0.05$ ) and the average percentage of baseline firing in the first 200 $\mathrm{ms}(21.4 \pm 5.0$ vs $37.6 \pm 7.6 \% ; p<0.05)$. These effects contrast with the effects of NAc DBS on MD-evoked inhibition, in which no changes were seen in mean onset of inhibition $(46.3 \pm 10.0$ vs $46.0 \pm 9.1$ ms; NS), duration of inhibition (95.4 \pm 18.7 vs $93.3 \pm 28.3 \mathrm{~ms}$; NS), number of spikes $(27.2 \pm 8.9$ vs $36.6 \pm 9.7$ spikes; NS), or percentage of baseline firing $(67.2 \pm 25.9$ vs $76.6 \pm 29.4 \%$; NS $)$ in the first $200 \mathrm{~ms}$ after stimulus after $30 \mathrm{~min}$ of NAc DBS (Fig. 3B).

The effects of DBS on NAc-evoked inhibition varied according to neuronal subpopulation in a manner similar to the effects of DBS on spontaneous activity. Specifically, putative interneurons and neurons excited by MD showed less suppression of inhibition after DBS than putative pyramidal neurons or neurons that did not receive excitatory monosynaptic input from MD (Table 1).

\section{Excitation}

Mean excitatory responses evoked by single-pulse NAc stimulation were unchanged after $30 \mathrm{~min}$ NAc DBS $(n=7)$ (Fig. $4 A)$. No significant differences were seen in evoked spike probability $(37.1 \pm 14.2$ vs $34.6 \pm 12.3 \%$; NS), number of evoked spikes (51.3 \pm 19.1 vs $46.4 \pm 19.4$; NS), or percentage of baseline firing ( $2976.2 \pm 1199.1$ vs $560.0 \pm 150.4 \%$; NS) in the first $25 \mathrm{~ms}$ after stimulus. However, when grouped according to cell type, four of four putative interneurons showed an increase in evoked spike probability. In contrast, after NAc DBS, MD-evoked shortlatency responses $(n=13)$ (Fig. $4 B)$ were strongly enhanced. This occurred as significant increases in evoked spike probability $(37.8 \pm 4.2$ vs $55.7 \pm 5.9 \% ; p<0.05)$, number of spikes in the first $25 \mathrm{~ms}$ after stimulus $(14.4 \pm 3.2$ vs $23.3 \pm 4.3 ; p<0.05)$, and percentage of baseline firing in the first $25 \mathrm{~ms}$ after stimulus
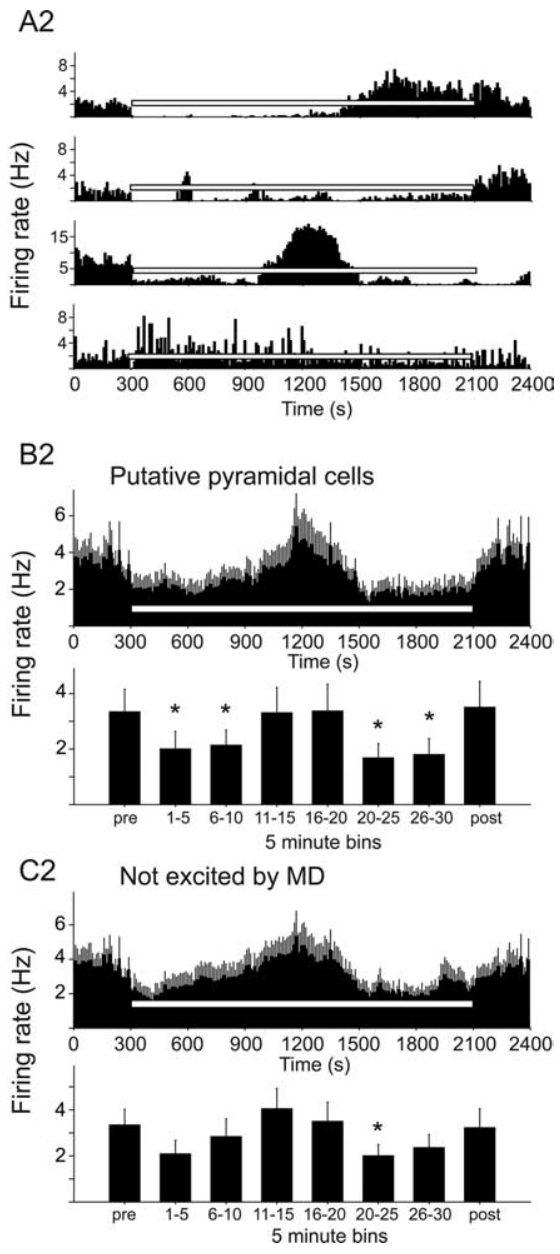

Figure 2. Thirty minutes of DBS produces a general inhibition of OFC neuronal firing. the open bar indicates DBS-on. A1, Top, Summed histogram showing DBS effects on all recorded neurons ( $n=30 ; 10$ s bins). Bottom, DBS effects on OFC activity, grouped 5 min bins. A2, Firing rate histograms for four individual neurons (10 s bins). The bottom panel is a putative interneuron. $\boldsymbol{B} \boldsymbol{C}_{\text {, }}$ putative pyramidal neurons in OFC (10 s bins; $n=20)$. Bottom, Five minute bins. C1, Top, NAC DBS effects on OFC neurons receiving monosynaptic MD input (10 s bins; $n=13$ ). Bottom, Five minute bins. 2 , Top, NAc DBS effects on OFC neurons not excited by MD (10 s bins; $n=17$ ). Bottom, Five minute bins. Error bars represent SEM. ${ }^{*} p<0.05$.

$(435.0 \pm 95.1$ vs $693.3 \pm 117.1 ; p<0.05)$. Both putative interneurons and putative pyramidal neurons showed this enhancement of excitation. To examine the source of the evoked responses, the effects of an electrolytic lesion of the NAc stimulation site on MD-evoked excitation was examined. Lesions of the NAc stimulation site did not affect any measure of MDevoked excitation $(n=4)$. Two of these neurons had been driven by both NAc and MD stimulation; after a NAc lesion, only the NAc responses were abolished, indicating that NAc-evoked effects are not attributable to stimulation of ascending $\mathrm{MD} \rightarrow \mathrm{OFC}$ fibers.

\section{Spontaneous LFP activity}

Spontaneous oscillatory LFP activity was quantified in a number of frequency bands before, during [early (in the first 5 min of DBS) and late (after $25 \mathrm{~min})]$, and after HF $(130 \mathrm{~Hz})$ or LF (10 $\mathrm{Hz}$ ) DBS. HF DBS produced a significant increase in the raw power of LF $\left(0.5-4 \mathrm{~Hz}\right.$, slow/delta) LFP oscillations $\left(F_{(3,24)}=\right.$ $6.33 ; p=0.008 ; n=9$ ) (Fig. $5 A$ ), as well as in the power in this frequency band when expressed as a percentage of total power $\left(\chi^{2}=11.93 ; \mathrm{df}=3 ; p=0.008 ; n=9\right)$. Post hoc analysis revealed that both raw and normalized power of these LF oscillations was 
A

NAc-evoked inhibition
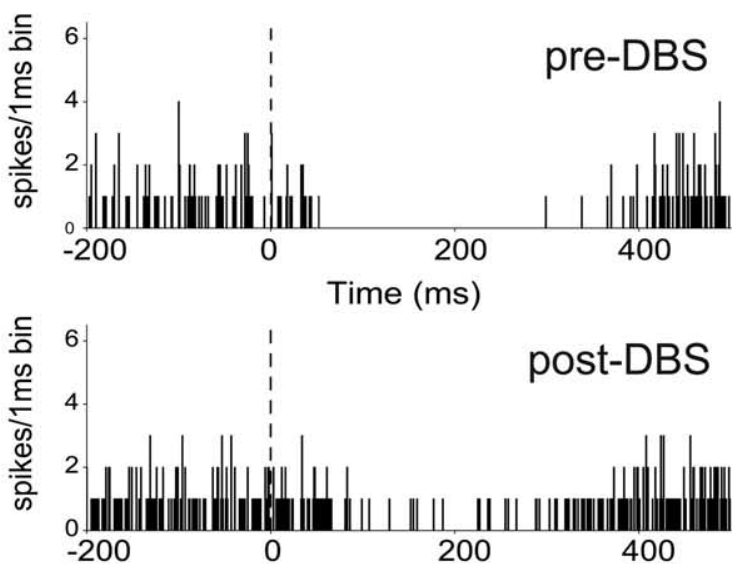

Time (ms)
B

MD-evoked inhibition
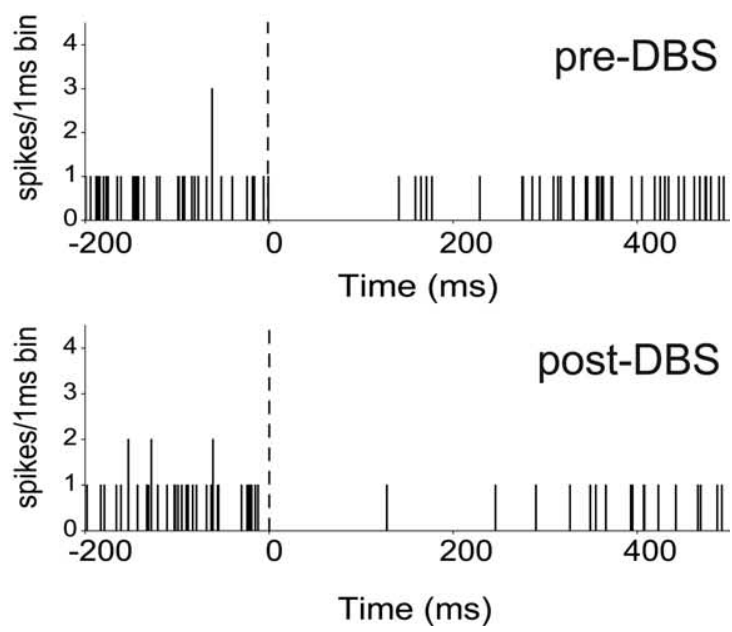

Figure 3. NAC DBS selectively attenuates NAc-evoked inhibition of OFC neurons. A, Peristimulus time histogram (PSTH) of an OFC neuron showing NAc-evoked inhibition before (top) and after (bottom) $30 \mathrm{~min}$ NAc DBS. PSTHs were constructed from 50 sweeps. The dashed line indicates time of stimulation. $\boldsymbol{B}$, PSTH of a representative OFC neuron showing MD-evoked inhibition before (top) and after (bottom) 30 min NAC DBS. The dashed line indicates time of stimulation.

Table 1. Effect of NAC DBS on single-pulse NAc-evoked inhibition

\begin{tabular}{|c|c|c|c|c|c|c|c|c|c|c|c|c|}
\hline & \multicolumn{3}{|l|}{ Onset (ms) } & \multicolumn{3}{|l|}{ Duration (ms) } & \multicolumn{3}{|c|}{ Spikes (first $200 \mathrm{~ms}$ ) } & \multicolumn{3}{|c|}{ Percentage of BL (first $200 \mathrm{~ms}$ ) } \\
\hline & Pre-DBS & Post-DBS & $p$ value & Pre-DBS & Post-DBS & $p$ value & Pre-DBS & Post-DBS & $p$ value & Pre-DBS & Post-DBS & $p$ value \\
\hline Putative interneuron $(n=7)$ & $28.57(7.46)$ & $41.78(12.90)$ & 0.098 & $196.58(44.13)$ & $125.07(32.31)$ & 0.066 & $11.43(6.43)$ & $11.86(5.6)$ & 0.92 & $18.15(6.1)$ & $25.76(9.93)$ & 0.117 \\
\hline Putative pyramidal neuron $(n=20)$ & $25.61(9.09)$ & $29.49(7.64)$ & 0.210 & $280.20(29.56)$ & $164.26(18.39)$ & 0.001 & $5.24(11.23)$ & $11.43(4.16)$ & 0.038 & $17.42(5.34)$ & $29.64(6.91)$ & 0.033 \\
\hline Excited by MD $(n=13)$ & 39.09 (12.31) & $41.29(10.08)$ & 0.278 & $227.38(38.03)$ & $132.28(23.58)$ & 0.005 & $12.00(3.95)$ & $17.71(6.22)$ & 0.414 & $23.77(5.74)$ & $66.25(29.29)$ & 0.089 \\
\hline Not excited by MD ( $n=17)$ & $13.71(4.87)$ & $23.12(7.49)$ & 0.047 & $288.05(30.54)$ & $174.18(19.55)$ & 0.001 & $1.47(0.47)$ & $5.20(1.50)$ & 0.040 & $9.34(5.61)$ & $22.13(6.17)$ & 0.018 \\
\hline
\end{tabular}

Values represent mean (SEM). Significant $p$ values are in bold type. BL, Baseline.

A

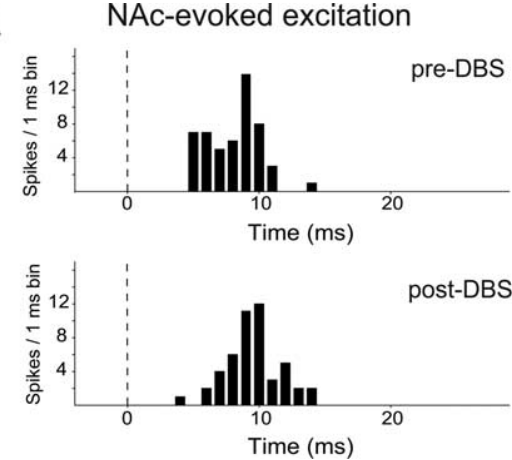

B

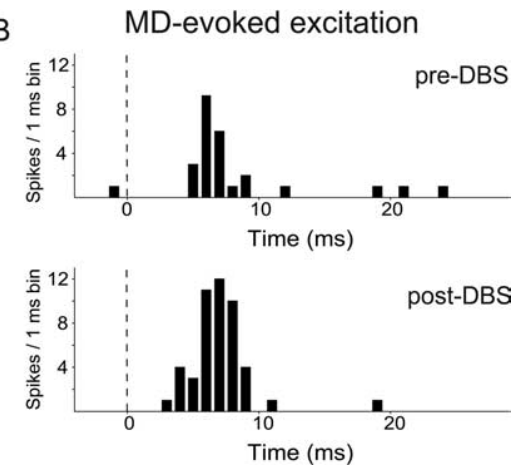

Figure 4. NAC DBS augments MD-evoked excitation in OFC without affecting NAc-evoked excitation. $\boldsymbol{A}$, PSTH of an OFC neuron showing NAc-evoked excitation before (top) and after (bottom) 30 min NACDBS. PSTHs were constructed from 50 sweeps. The dashed line indicates time of stimulation. $\boldsymbol{B}$, PSTH of a representative OFC neuron showing MD-evoked excitation before (top) and after (bottom) $30 \mathrm{~min}$ NAc DBS. PSTHs were constructed from 50 sweeps. The dashed line indicates time of stimulation.

significantly elevated after DBS. There was a trend $(p=0.08)$ toward an increase in power in the last $5 \mathrm{~min}$ of DBS, suggesting that this effect developed over the course of the DBS-on period as opposed to being a compensatory change after DBS. No changes in raw or normalized power were observed in any other frequency band (i.e., theta, beta, gamma). These results contrast with those obtained with LF DBS [known to be ineffective for treating most neurological and psychiatric disorders (Perlmutter and Mink, 2006)], in which no significant changes in power were seen in any frequency band $(n=5)$ (Fig. $5 B)$.

\section{Evoked LFP activity}

Stimulation of either the NAc or MD produced robust short-latency LFP responses in OFC. Both of these responses were characterized by a large negative-going voltage deflection (mean latency to peak: NAc evoked, $4.35 \pm 0.16 \mathrm{~ms}$; MD evoked, $6.11 \pm 0.14 \mathrm{~ms}$ ). Local infusion of kynurenic acid almost completely abolished the negative-going component of the LFP response evoked from either NAc or MD $(n=3)$ (Fig. $6 A 1)$, suggesting that this component is primarily glutamatergic. Conversely, local infusion of bicuculline virtually eliminated the positive-going component of the LFP response evoked from either region $(n=3)$ (Fig. 6A2), producing instead a secondary large-amplitude (presumably excitatory) negative-going component. Vehicle infusions had no effects on the evoked LFP responses. The NAc-evoked responses likely correspond to antidromic activation of local recurrent corticostriatal fiber collaterals, because there are projections from the OFC that terminate in this region (Gabbott et al., 2005) and there are no known direct projections from NAc to OFC. The MD-evoked responses likely reflect orthodromic and monosynaptic activation of OFC neurons, because the latency of the peak field response corresponds roughly to reported thalamocortical (as opposed to corticothalamic) conduction velocities [i.e., $\sim 5 \mathrm{~ms}$ (Pirot et al., 1994)].

To assess the effects of NAc DBS on these evoked LFP re- 
A1 $130 \mathrm{~Hz}$ NAc DBS

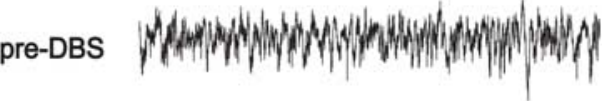

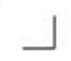

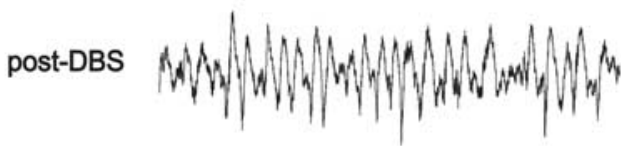

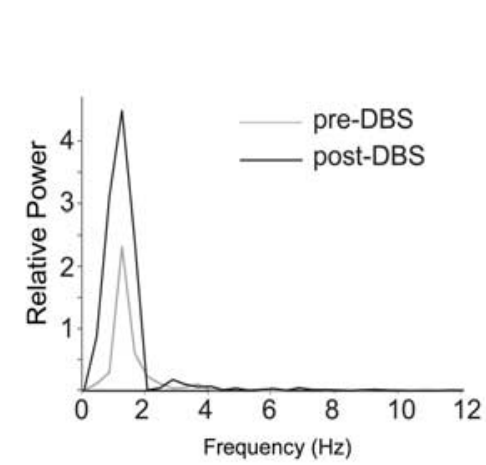

A2

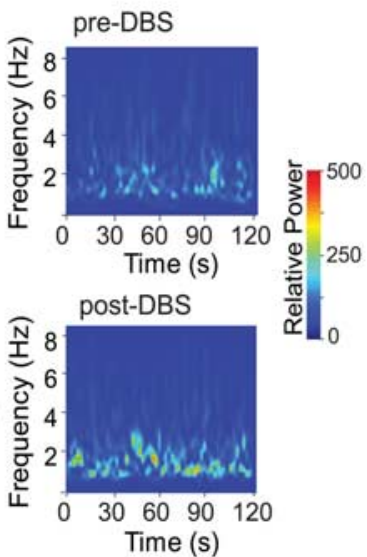

Raw Power: 0.5 - $4 \mathrm{~Hz} \quad \%$ of Total Power: $0.5-4 \mathrm{~Hz}$
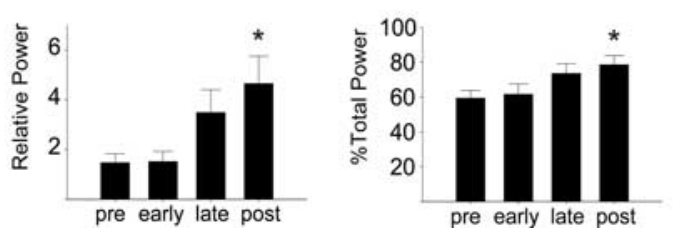

B1

\section{$10 \mathrm{~Hz}$ NAc DBS}

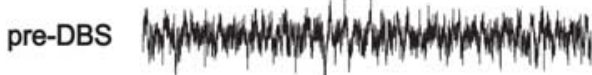

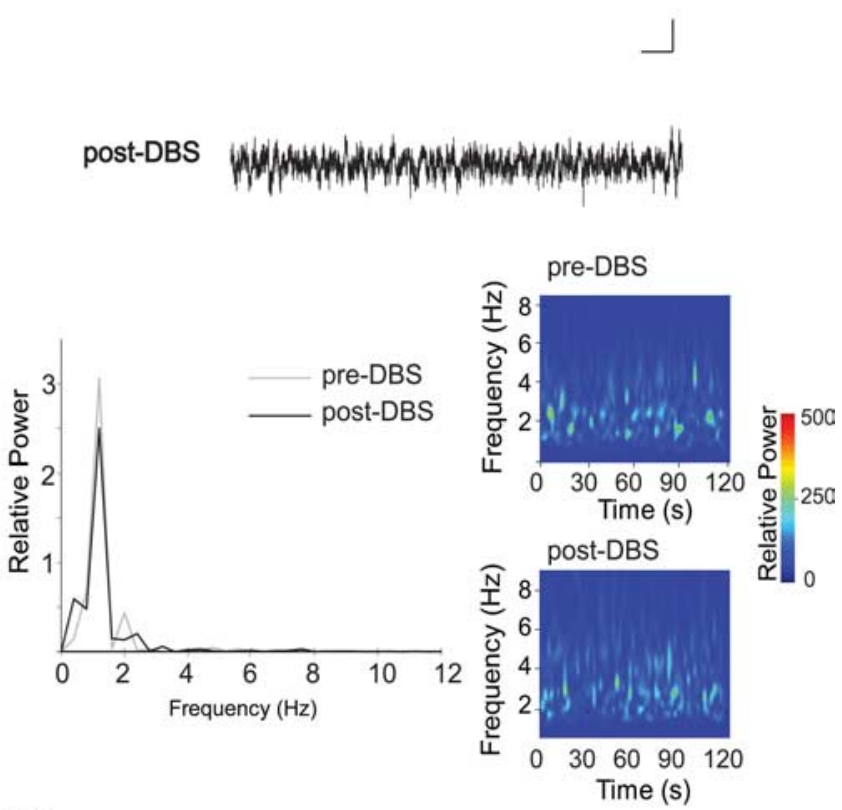

B2

Figure 5. HF but not LF NAC DBS enhances spontaneous LFP slow oscillatory activity in OFC. A1, Top, OFC voltage trace before (top) and after (bottom) $30 \mathrm{~min} 130 \mathrm{~Hz}$ NAC DBS. Bottom left, Periodogram constructed from $2 \mathrm{~min}$ of spontaneous OFC LFP activity before (gray) and after (black) $30 \mathrm{~min}$ NAC DBS. Bottom right, Spectrograms showing changes in OFC oscillatory activity across time. Spectograms were constructed from 2 min of spontaneous OFC LFP activity before (top) and after (bottom) $30 \mathrm{~min}$ NAc DBS. A2, Left, Total raw power in the $0.5-4 \mathrm{~Hz}$ frequency band before DBS, during the first 5 min of DBS-on, during the last 5 min of DBS-on (i.e., minutes $26-30$ ), and after DBS $(n=7)$ ). Right, Power in the $0.5-4$ Hz band expressed as percentage of total power before DBS, during the first 5 min of DBS-on, during the last 5 min of DBS-on (i.e., minutes $26-30$ ), and after DBS $(n=7){ }^{*} p<0.05$. B1, Top, 0 FC voltage trace before (top) and after (bottom) 30 min $10 \mathrm{~Hz} \mathrm{NAc} \mathrm{DBS}$. Bottom left, Periodogram constructed from $2 \mathrm{~min}$ of spontaneous OFC LFP activity before (gray) and after (black) 30 min NAc DBS. Bottom right, Spectrograms showing changes in OFC oscillatory activity across time. Spectograms were constructed from $2 \mathrm{~min}$ of spontaneous OFC LFP activity before (top) and after (bottom) $30 \mathrm{~min} 10 \mathrm{~Hz} \mathrm{NAC} \mathrm{DBS} \mathrm{(} n=5$ ). B2, Left, Total raw power in the $0.5-4 \mathrm{~Hz}$ frequency band before and after $10 \mathrm{~Hz} \mathrm{NACDBS}$. Right, Power in the $0.5-4 \mathrm{~Hz}$ band expressed as percentage of total power, before and after $10 \mathrm{~Hz}$ NAC DBS $(n=5)$. Error bars indicate SEM.

sponses, input-output curves from each electrode were generated before DBS and both 5 and 90 min after HF DBS and LF DBS (Fig. 7). Two-way ANOVA with current intensity as a repeated measure revealed a main effect of time after DBS $\left(F_{(2,48)}=4.29\right.$; $p=0.03)$ and current intensity $\left(F_{(2,48)}=51.864 ; p<0.001\right)$ with no interaction between time after DBS and intensity $\left(F_{(2,48)}=\right.$ 1.01 ; NS). Post hoc analysis revealed that HF DBS produced a significant potentiation of NAc-evoked LFP amplitude both 5 and $90 \mathrm{~min}$ after DBS at all, except for the lowest, stimulation intensity. MD-evoked responses were unaffected at all time points. Conversely, LF DBS failed to produce an effect on evoked responses from either region at any stimulation intensity or time point. Given the reliance of long-term potentiation (LTP)-like processes on NMDA receptors, we also assessed the effects of HF DBS on evoked LFP activity in the presence of the NMDA antagonist MK-801. Pretreatment with MK-801 (1.0 mg/kg, i.p.) 30 min before DBS did not affect the LFP evoked from either NAc or
MD but completely blocked the potentiating effects of HF DBS on NAc-evoked LFP activity $(n=4)$ (Fig. 7$)$.

\section{Discussion}

NAc DBS, delivered at clinically effective frequencies and intensities, reduces OFC neuronal firing, selectively modulates afferent input to OFC measured by single-unit and evoked LFPs, and alters OFC LFP oscillatory activity in vivo. We propose that this occurs via activation of recurrent inhibitory processes within the OFC that are selectively potentiated during DBS.

\section{Parallels between rodent DBS and therapeutic approaches} in humans

Successful DBS treatment of OCD patients is associated with reductions in aberrant metabolism in the OFC (Nuttin et al., 2003; Abelson et al., 2005). Studies suggest that the rat and human OFC are functionally analogous based on connectivity (Leonard, 1969; 


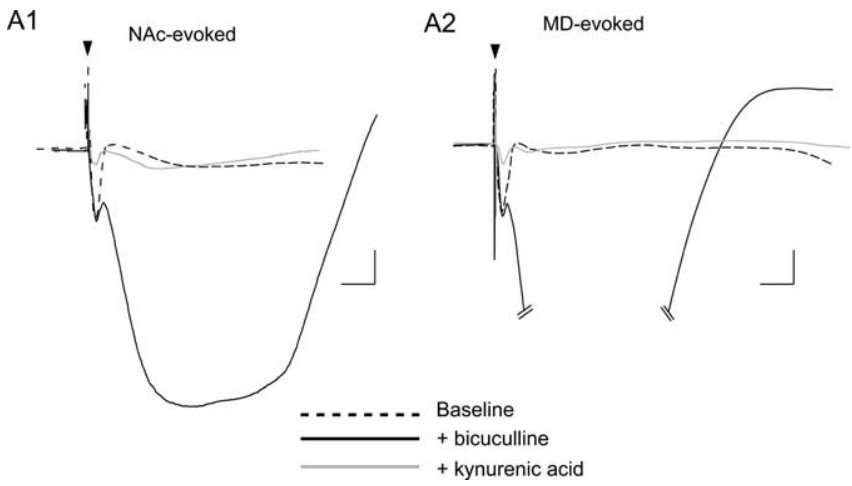

Figure 6. Effects of ionotropic GABA or glutamate receptor blockade on NAc-evoked (A1) and MD-evoked (A2) LFP responses. Blockade of fast glutamatergic transmission with kynurenic acid greatly attenuated the LFP evoked from either NAc or MD stimulation. In contrast, blockade of ionotropic GABA receptors with bicuculline eliminated the positive-going component of the LFP response and instead produced a large-amplitude secondary negativegoing component. Arrowheads indicate time of stimulation. Calibration: $10 \mathrm{~ms}, 30 \mathrm{mV}$.

Krettek and Price, 1977; Groenewegen, 1988). Although some debate exists, the area consisting of the ventral orbital (VO), lateral orbital (LO), and agranular insular (AI) cortices is reported to be most homologous to the primate OFC (Ongur and Price, 2000; Schoenbaum et al., 2006). We recorded from neurons in $\mathrm{LO}$ and ventral AI because these areas are the source of $\mathrm{OFC} \rightarrow \mathrm{NAc}$ fibers, with $\mathrm{VO}$ having relatively sparse projections to the NAc (Gabbott et al., 2005). The stimulating electrode was targeted to the dorsal NAc core. A common DBS target in human OCD patients is the ventral anterior internal capsule (Nuttin et al., 2003; Abelson et al., 2005; Greenberg et al., 2006); however, recently therapeutic responses have been achieved by targeting the NAc (Sturm et al., 2003; Aouizerate et al., 2005), supporting the validity of our stimulation target in the rat. Although difficult to precisely replicate human parameters, current intensities were modeled after the human literature, and in the range used effectively in animal models of Parkinson's disease (Chang et al., 2003; Degos et al., 2005). Moreover, these stimulation parameters produced profound effects on neuronal firing without observable tissue trauma. The dearth of robust animal models of OCD makes it difficult to judge whether these intensities have beneficial behavioral effects; nonetheless, we feel the present results yield pertinent data regarding the effects of DBS on neuronal activity. Indeed, whereas the current study was performed in animals with no obvious pathology, we believe that the plastic changes induced by direct stimulation are likely to produce the same circuit-level effects as those elicited in the clinic.

\section{Spontaneous neuronal activity}

The mean firing rate of OFC neurons was reduced during NAc DBS. This effect was most pronounced in putative pyramidal neurons; some putative interneurons showed excitatory responses to DBS. Moreover, single-pulse stimulation of the NAc DBS site resulted in a profound, rapid-onset inhibition of firing in almost every OFC neuron encountered, with many of these neurons exhibiting antidromic activation from the NAc. The rapid onset of inhibition (i.e., $>50 \%$ of neurons showed total inhibition within $15 \mathrm{~ms}$ of stimulation) suggests that this acute inhibition does not arise from a polysynaptic feedforward effect. Furthermore, there are no direct projections from NAc to OFC, as opposed to the substantial OFC $\rightarrow$ NAc projection (Gabbott et al., 2005). Finally, given that an electrolytic lesion of the DBS site does not interrupt MD-evoked responses in OFC, it is unlikely

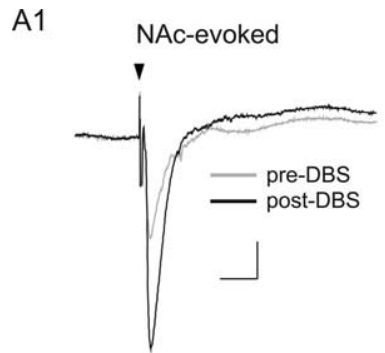

B1
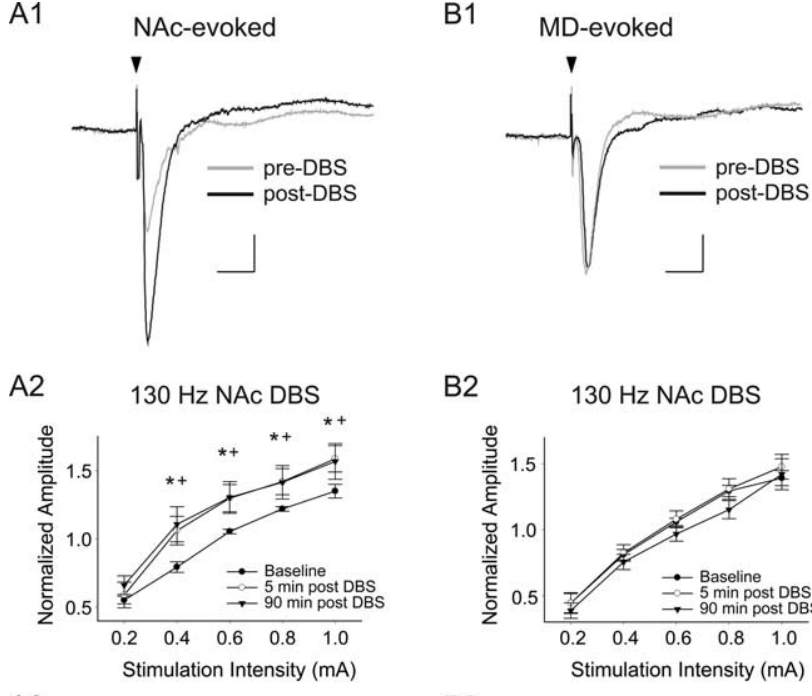

A3

$10 \mathrm{~Hz}$ NAc DBS

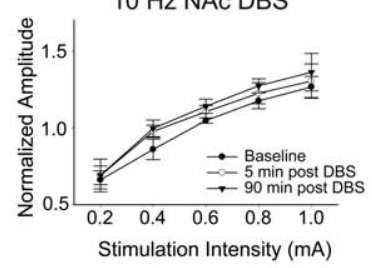

A4 $130 \mathrm{~Hz}$ NAc DBS + MK-801

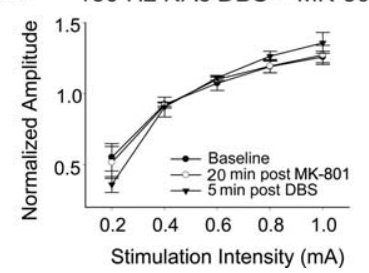

B2

$130 \mathrm{~Hz}$ NAc DBS

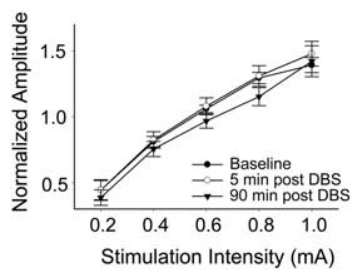

B3

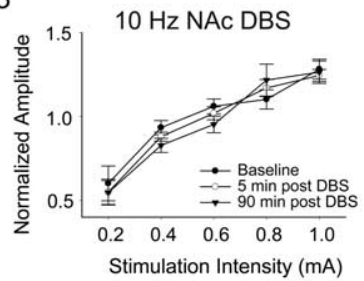

B4

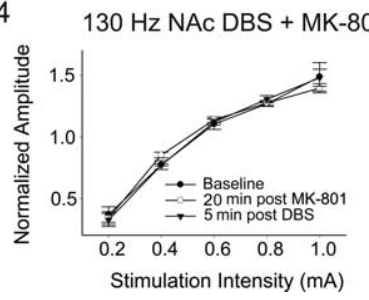

Figure 7. HF but not LF NAC DBS selectively potentiates NAC-evoked LFP responses in OFC. A1, Voltage trace showing a NAc-evoked LFP response before (gray) and after (black) $30 \mathrm{~min}$ NAC DBS. Arrowheads indicate time of stimulation. Calibration: $10 \mathrm{~ms}, 30 \mathrm{mV}$. A2, Inputoutput curves for NAc-evoked OFC LFP responses before DBS, 5 min after DBS, and 90 min after DBS $\left({ }^{*} p<0.05\right.$ for pre-DBS vs 20 min post-DBS; ${ }^{+} p<0.05$ for pre-DBS vs 5 min post-DBS; $n=7)$. $A 3$, Input- output curves for NAc-evoked LFP responses before $10 \mathrm{~Hz}$ DBS, 5 min after 10 $\mathrm{Hz} \mathrm{DBS}$, and $90 \mathrm{~min}$ after $10 \mathrm{~Hz} \mathrm{DBS}(n=5)$. A4, Input-output curves for NAc-evoked LFP responses at baseline, $20 \mathrm{~min}$ after $1.0 \mathrm{mg} / \mathrm{kg} \mathrm{MK}-801$, and $5 \mathrm{~min}$ after DBS $(130 \mathrm{~Hz})(n=4)$. $B 1$, The voltage trace showed an MD-evoked OFC LFP response before (gray) and after (black) 30 min NAc DBS. Calibration: $10 \mathrm{~ms}, 30 \mathrm{mV}$. B2, Input- output curves for MD-evoked LFP responses before DBS, 5 min after DBS, and 90 min after DBS $(n=7)$. B3, Input- output curves for MD-evoked LFP responses before $10 \mathrm{~Hz}$ DBS, 5 min after $10 \mathrm{~Hz}$ DBS, and 90 min after $10 \mathrm{~Hz}$ DBS $(n=5) . \boldsymbol{B} 4$, Input-output curves for MD-evoked LFP responses at baseline, $20 \mathrm{~min}$ after 1.0 $\mathrm{mg} / \mathrm{kg} \mathrm{MK}-801$, and $5 \mathrm{~min}$ after $130 \mathrm{~Hz}$ DBS $(n=4)$.

that the acute inhibitory response reflects activation of $\mathrm{MD} \rightarrow$ OFC fibers traversing the NAc. Thus, these data are consistent with NAc stimulation driving recurrent inhibition in OFC via antidromic activation of corticostriatal axons. We focused exclusively on neurons that responded to acute NAc stimulation, because assessing the effects of DBS on evoked activity requires an appreciable level of responsivity to stimulation. Moreover, by limiting our analysis to neurons exhibiting some evoked activity, we ensured that we were in the appropriate projection field for the neuron under investigation.

Antidromically driven recurrent inhibition is a well characterized phenomenon that has been documented in several cortical regions, including motor cortex (Phillips, 1959), visual cortex (Feeney and 
Orem, 1971), and hippocampus (Matsuda and Fujimura, 1996). In layer $\mathrm{V}$ pyramidal neurons of the motor cortex, antidromic activation of efferent fiber tracts produces predominantly IPSPs mediated by recurrent collaterals (Phillips, 1959; Stefanis and Jasper, 1964). Whereas demonstration of NAc stimulation-mediated excitation is limited in the current study because of the small number of putative interneurons recorded, a subset of these putative interneurons did exhibit reliable excitatory responses to acute NAc stimulation, and an increase in firing to NAc DBS.

\section{Evoked neuronal activity}

After DBS, NAc-evoked inhibitory responses were generally attenuated, with this suppression most prominent in neurons that were strongly inhibited during DBS, whereas evoked inhibition of putative interneurons was enhanced. In contrast, neurons receiving direct MD input were not significantly affected by DBS. MD-evoked inhibitory responses were unchanged after DBS, whereas excitatory responses (in putative interneurons and pyramidal neurons) were potentiated. These results suggest that DBS preferentially affects specific subpopulations of neurons, with a potentiation of evoked excitatory input to interneurons after DBS. This increased drive onto putative interneurons may reflect an LTP-like phenomenon produced by DBS, in which stimulation frequencies (i.e., $130 \mathrm{~Hz}$ ) are consistent with those required for induction of LTP (Bliss and Collingridge, 1993).

\section{Spontaneous LFP activity}

LFP responses represent summed dendritic synaptic activity over a relatively large area and hence provide a measure of input to a region (Mitzdorf, 1985; Logothetis, 2003). Slow LFP oscillations $(0.5-4 \mathrm{~Hz})$ in neocortex occur during sleep and with certain anesthetics (Metherate and Ashe, 1993; Steriade et al., 1993; Cowan and Wilson, 1994; Amzica and Steriade, 1998) and reflect synchronous changes in membrane potential caused by recurrent cortical activity (Sanchez-Vives and McCormick, 2000; Shu et al., 2003). Analysis of the spectral density in this frequency band revealed an increase in power that developed during DBS. This increase in power may stem from sustained activation of corticostriatal axons by NAc DBS that would, in turn, drive recurrent activity in OFC. In contrast, $10 \mathrm{~Hz}$ DBS had no effect on slow LFP oscillations in OFC, arguing against anesthesia-related effects. Moreover, given the reported lack of efficacy of LF DBS on OCD symptoms, the enhancement of slow oscillations by HF DBS may be significant for therapeutic effects. Interestingly, DBS of the subthalamic nucleus in parkinsonian patients increases slow LFP oscillations within this region (Priori et al., 2006).

\section{Evoked LFP responses}

Single-pulse stimulation of either the NAc or MD resulted in robust short-latency LFP responses in OFC, presumably reflecting the synchronous activation of an afferent input. Given the lack of direct projections from NAc to OFC, the NAc-evoked response is likely attributable to antidromic activation of corticostriatal fibers. In contrast, the latency of the MD-evoked response is consistent with an orthodromic monosynaptic input, because conduction velocities of corticothalamic fibers are considerably longer than that of thalamocortical fibers (Pirot et al., 1994). The negative-going component of the LFP responses is glutamatergic, because LFP responses were greatly attenuated after local ionotropic glutamate receptor blockade. The positive-going component of the LFP response was eliminated after $\mathrm{GABA}_{\mathrm{A}}$ receptor blockade and thus likely represents a GABAergic event produced by recurrent (with NAc stimulation) or orthodromic and recur-

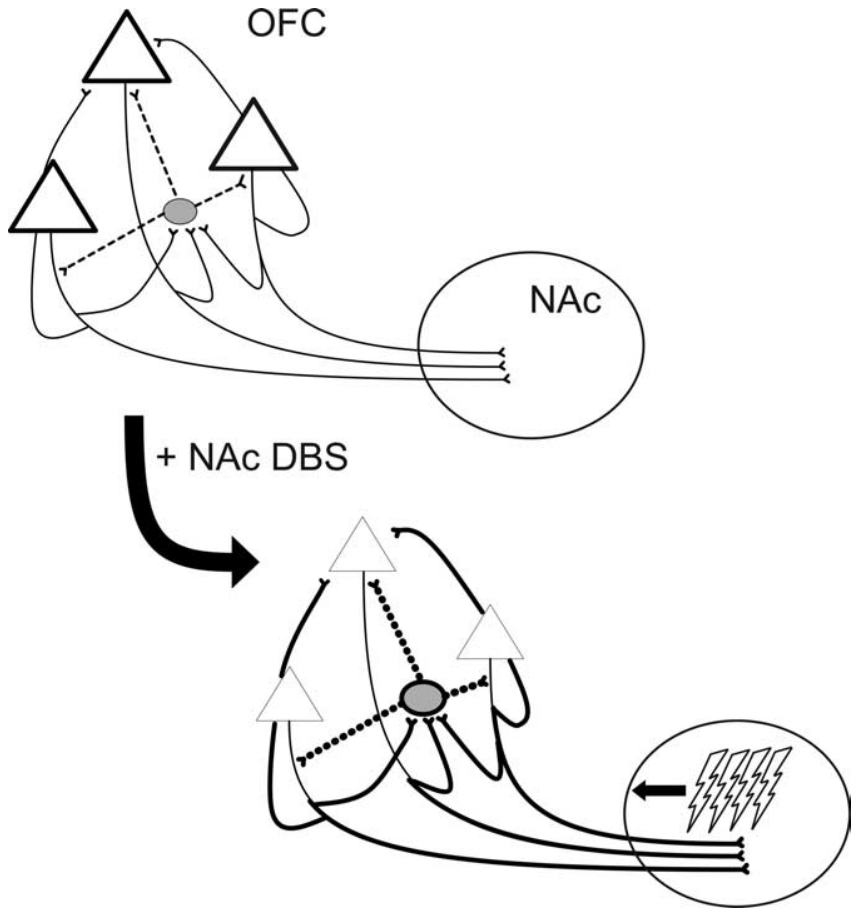

Figure 8. Schematic of the proposed mechanism of action of NAC DBS on OFC neuron activity. NAC DBS produces antidromic activation of corticostriatal projections that activate a population of interneurons (circle) via recurrent collaterals. These interneurons in turn suppress firing in populations of pyramidal neurons (triangles). With maintained HF stimulation, this would induce an LTP in this recurrent inhibitory pathway (bold lines). Although certain pyramidal neurons would receive excitatory input from these same recurrent collaterals, inhibitory inputs are positioned [e.g., by targeting the soma or axon initial segment (Markram et al., 2004)] to potently suppress the activity of these output neurons.

rent (with MD stimulation) activation of OFC interneurons. Blockade of $\mathrm{GABA}_{\mathrm{A}}$ receptors eliminates both feedforward and recurrent inhibition, unmasking a robust secondary (recurrent) negative-going excitation. The amplitude of NAc-evoked LFP responses was potentiated after $\mathrm{HF}$ but not LF $(10 \mathrm{~Hz})$ DBS and remained elevated for at least $90 \mathrm{~min}$. This DBS-induced potentiation was prevented by NMDA receptor blockade. The amplitude of MD-evoked LFPs did not change with any manipulation.

This evidence is consistent with tetanic stimulation-induced potentiation of excitatory drive mediated by recurrent collaterals. Thus, Phillips (1959) reported that subthreshold antidromic tetanic stimulation potentiated EPSPs mediated by recurrent collaterals. Moreover, potentiation of the NAc-evoked LFP response required HF stimulation and was dependent on NMDA receptor activation. Together, these data suggest an LTP-like potentiation of antidromically stimulated recurrent collaterals of pyramidal neuron axons and is consistent with the requirement for HF stimulation in the LTP range [i.e., $>100 \mathrm{~Hz}$ (Bliss and Collingridge, 1993)] to produce therapeutic effects.

\section{Implications}

We propose that the effects of NAc DBS on OFC activity are mediated by antidromic activation of recurrent OFC collaterals, causing excitation of inhibitory interneurons and consequent suppression of principal cell output (in effect, "hijacking" the machinery mediating physiological recurrent inhibition) (Fig. 8). Indeed, antidromic activation of branched axons may mediate certain effects produced by DBS for movement disorders (Maurice et al., 2003; Grill et al., 2007). Furthermore, our model is 
consistent with the therapeutic responses produced by DBS in OCD patients (i.e., normalization of OFC metabolic hyperactivity). Considering that sustained antidromic activation of corticostriatal fibers by NAc DBS will also suppress orthodromic impulses, OFCstriatal output may be reduced further still. DBS within this circuit has also been effective in the treatment of other disorders, including DBS of the subgenual cingulate gyrus for depression (Mayberg et al., 2005) and DBS of the NAc/internal capsule (Flaherty et al., 2005; Kuhn et al., 2007), thalamus (Visser-Vandewalle et al., 2003), and globus pallidus (Ackermans et al., 2006; Shahed et al., 2007) for Tourette's syndrome, which is often comorbid with OCD (Jankovic, 2001). Therefore, by altering the balance of excitation/inhibition within cortical efferent pathways, DBS may prove to have a more general effect of stabilizing disordered systems in a manner that may be generally applicable to patients exhibiting functional deficits within these circuits.

\section{References}

Abelson JL, Curtis GC, Sagher O, Albucher RC, Harrigan M, Taylor SF, Martis B, Giordani B (2005) Deep brain stimulation for refractory obsessivecompulsive disorder. Biol Psychiatry 57:510-516.

Ackermans L, Temel Y, Cath D, van der Linden C, Bruggeman R, Kleijer M, Nederveen P, Schruers K, Colle H, Tijssen MA, Visser-Vandewalle V (2006) Deep brain stimulation in Tourette's syndrome: two targets? Mov Disord 21:709-713.

Amzica F, Steriade M (1998) Electrophysiological correlates of sleep delta waves. Electroencephalogr Clin Neurophysiol 107:69-83.

Anderson D, Ahmed A (2003) Treatment of patients with intractable obsessive-compulsive disorder with anterior capsular stimulation. Case report. J Neurosurg 98:1104-1108.

Aouizerate B, Martin-Guehl C, Cuny E, Guehl D, Amieva H, Benazzouz A, Fabrigoule C, Bioulac B, Tignol J, Burbaud P (2005) Deep brain stimulation for OCD and major depression. Am J Psychiatry 162:2192.

Baxter Jr LR, Schwartz JM, Mazziotta JC, Phelps ME, Pahl JJ, Guze BH, Fairbanks L (1988) Cerebral glucose metabolic rates in nondepressed patients with obsessive-compulsive disorder. Am J Psychiatry 145:1560-1563.

Benabid AL, Pollak P, Gervason C, Hoffmann D, Gao DM, Hommel M, Perret JE, de Rougemont J (1991) Long-term suppression of tremor by chronic stimulation of the ventral intermediate thalamic nucleus. Lancet 337:403-406.

Benabid AL, Pollak P, Gross C, Hoffmann D, Benazzouz A, Gao DM, Laurent A, Gentil M, Perret J (1994) Acute and long-term effects of subthalamic nucleus stimulation in Parkinson's disease. Stereotact Funct Neurosurg 62:76-84

Benazzouz A, Gao DM, Ni ZG, Piallat B, Bouali-Benazzouz R, Benabid AL (2000) Effect of high-frequency stimulation of the subthalamic nucleus on the neuronal activities of the substantia nigra pars reticulata and ventrolateral nucleus of the thalamus in the rat. Neuroscience 99:289-295.

Beurrier C, Bioulac B, Audin J, Hammond C (2001) High-frequency stimulation produces a transient blockade of voltage-gated currents in subthalamic neurons. J Neurophysiol 85:1351-1356.

Bliss TV, Collingridge GL (1993) A synaptic model of memory: long-term potentiation in the hippocampus. Nature 361:31-39.

Boraud T, Bezard E, Bioulac B, Gross C (1996) High frequency stimulation of the internal globus pallidus (GPi) simultaneously improves parkinsonian symptoms and reduces the firing frequency of GPi neurons in the MPTP-treated monkey. Neurosci Lett 215:17-20.

Breiter HC, Rauch SL, Kwong KK, Baker JR, Weisskoff RM, Kennedy DN, Kendrick AD, Davis TL, Jiang A, Cohen MS, Stern CE, Belliveau JW, Baer L, O'Sullivan RL, Savage CR, Jenike MA, Rosen BR (1996) Functional magnetic resonance imaging of symptom provocation in obsessivecompulsive disorder. Arch Gen Psychiatry 53:595-606.

Chang JY, Shi LH, Luo F, Woodward DJ (2003) High frequency stimulation of the subthalamic nucleus improves treadmill locomotion in unilateral 6-hydroxydopamine lesioned rats. Brain Res 983:174-184.

Cowan RL, Wilson CJ (1994) Spontaneous firing patterns and axonal projections of single corticostriatal neurons in the rat medial agranular cortex. J Neurophysiol 71:17-32.

Degos B, Deniau JM, Thierry AM, Glowinski J, Pezard L, Maurice N (2005) Neuroleptic-induced catalepsy: electrophysiological mechanisms of func- tional recovery induced by high-frequency stimulation of the subthalamic nucleus. J Neurosci 25:7687-7696.

Deuschl G, Schade-Brittinger C, Krack P, Volkmann J, Schafer H, Botzel K, Daniels C, Deutschlander A, Dillmann U, Eisner W, Gruber D, Hamel W, Herzog J, Hilker R, Klebe S, Kloss M, Koy J, Krause M, Kupsch A, Lorenz D, et al. (2006) A randomized trial of deep-brain stimulation for Parkinson's disease. N Engl J Med 355:896-908.

Dostrovsky JO, Levy R, Wu JP, Hutchison WD, Tasker RR, Lozano AM (2000) Microstimulation-induced inhibition of neuronal firing in human globus pallidus. J Neurophysiol 84:570-574.

Feeney DM, Orem JM (1971) Influence of antidromic callosal volleys on single units in visual cortex. Exp Neurol 33:310-321.

Flaherty AW, Williams ZM, Amirnovin R, Kasper E, Rauch SL, Cosgrove GR, Eskandar EN (2005) Deep brain stimulation of the anterior internal capsule for the treatment of Tourette syndrome: technical case report. Neurosurgery 57:E403; discussion E403.

Floresco SB, Grace AA (2003) Gating of hippocampal-evoked activity in prefrontal cortical neurons by inputs from the mediodorsal thalamus and ventral tegmental area. J Neurosci 23:3930-3943.

Gabbott PL, Warner TA, Jays PR, Salway P, Busby SJ (2005) Prefrontal cortex in the rat: projections to subcortical autonomic, motor, and limbic centers. J Comp Neurol 492:145-177.

Gabriels L, Cosyns P, Nuttin B, Demeulemeester H, Gybels J (2003) Deep brain stimulation for treatment-refractory obsessive-compulsive disorder: psychopathological and neuropsychological outcome in three cases. Acta Psychiatr Scand 107:275-282.

Greenberg BD, Malone DA, Friehs GM, Rezai AR, Kubu CS, Malloy PF, Salloway SP, Okun MS, Goodman WK, Rasmussen SA (2006) Threeyear outcomes in deep brain stimulation for highly resistant obsessivecompulsive disorder. Neuropsychopharmacology 31:2384-2393.

Grill WM, Cantrell MB, Robertson MS (2007) Antidromic propagation of action potentials in branched axons: implications for the mechanisms of action of deep brain stimulation. J Comput Neurosci, in press.

Groenewegen HJ (1988) Organization of the afferent connections of the mediodorsal thalamic nucleus in the rat, related to the mediodorsalprefrontal topography. Neuroscience 24:379-431.

Jankovic J (2001) Tourette's syndrome. N Engl J Med 345:1184-1192.

Kiss ZH, Mooney DM, Renaud L, Hu B (2002) Neuronal response to local electrical stimulation in rat thalamus: physiological implications for mechanisms of deep brain stimulation. Neuroscience 113:137-143.

Krack P, Batir A, Van Blercom N, Chabardes S, Fraix V, Ardouin C, Koudsie A, Limousin PD, Benazzouz A, LeBas JF, Benabid AL, Pollak P (2003) Five-year follow-up of bilateral stimulation of the subthalamic nucleus in advanced Parkinson's disease. N Engl J Med 349:1925-1934.

Krettek JE, Price JL (1977) The cortical projections of the mediodorsal nucleus and adjacent thalamic nuclei in the rat. J Comp Neurol 171:157-191.

Kuhn J, Lenartz D, Mai JK, Huff W, Lee SH, Koulousakis A, Klosterkoetter J, Sturm V (2007) Deep brain stimulation of the nucleus accumbens and the internal capsule in therapeutically refractory Tourette-syndrome. J Neurol 254:963-965.

Laviolette SR, Lipski WJ, Grace AA (2005) A subpopulation of neurons in the medial prefrontal cortex encodes emotional learning with burst and frequency codes through a dopamine $\mathrm{D}_{4}$ receptor-dependent basolateral amygdala input. J Neurosci 25:6066-6075.

Leonard CM (1969) The prefrontal cortex of the rat. I. Cortical projection of the mediodorsal nucleus. II. Efferent connections. Brain Res 12:321-343.

Lian J, Bikson M, Sciortino C, Stacey WC, Durand DM (2003) Local suppression of epileptiform activity by electrical stimulation in rat hippocampus in vitro. J Physiol (Lond) 547:427-434.

Logothetis NK (2003) The underpinnings of the BOLD functional magnetic resonance imaging signal. J Neurosci 23:3963-3971.

Magarinos-Ascone C, Pazo JH, Macadar O, Buno W (2002) Highfrequency stimulation of the subthalamic nucleus silences subthalamic neurons: a possible cellular mechanism in Parkinson's disease. Neuroscience 115:1109-1117.

Markram H, Toledo-Rodriguez M, Wang Y, Gupta A, Silberberg G, Wu C (2004) Interneurons of the neocortical inhibitory system. Nat Rev Neurosci 5:793-807.

Matsuda Y, Fujimura K (1996) Recurrent inhibition in amygdalo-cortical projection neurons of the rat via collaterals of fast-conducting axons. Neurosci Res 25:385-389.

Maurice N, Thierry AM, Glowinski J, Deniau JM (2003) Spontaneous and 
evoked activity of substantia nigra pars reticulata neurons during highfrequency stimulation of the subthalamic nucleus. J Neurosci 23:9929-9936.

Mayberg HS, Lozano AM, Voon V, McNeely HE, Seminowicz D, Hamani C, Schwalb JM, Kennedy SH (2005) Deep brain stimulation for treatmentresistant depression. Neuron 45:651-660.

McGuire PK, Bench CJ, Frith CD, Marks IM, Frackowiak RS, Dolan RJ (1994) Functional anatomy of obsessive-compulsive phenomena. Br J Psychiatry 164:459-468.

McIntyre CC, Grill WM (1999) Excitation of central nervous system neurons by nonuniform electric fields. Biophys J 76:878-888.

McIntyre CC, Savasta M, Walter BL, Vitek JL (2004a) How does deep brain stimulation work? Present understanding and future questions. J Clin Neurophysiol 21:40-50.

McIntyre CC, Grill WM, Sherman DL, Thakor NV (2004b) Cellular effects of deep brain stimulation: model-based analysis of activation and inhibition. J Neurophysiol 91:1457-1469.

Metherate R, Ashe JH (1993) Ionic flux contributions to neocortical slow waves and nucleus basalis-mediated activation: whole-cell recordings in vivo. J Neurosci 13:5312-5323.

Mindus P, Ericson K, Greitz T, Meyerson BA, Nyman H, Sjogren I (1986) Regional cerebral glucose metabolism in anxiety disorders studied with positron emission tomography before and after psychosurgical intervention. A preliminary report. Acta Radiol Suppl 369:444-448.

Mitzdorf U (1985) Current source-density method and application in cat cerebral cortex: investigation of evoked potentials and EEG phenomena. Physiol Rev 65:37-100.

Nowak LG, Bullier J (1998a) Axons, but not cell bodies, are activated by electrical stimulation in cortical gray matter. I. Evidence from chronaxie measurements. Exp Brain Res 118:477-488.

Nowak LG, Bullier J (1998b) Axons, but not cell bodies, are activated by electrical stimulation in cortical gray matter. II. Evidence from selective inactivation of cell bodies and axon initial segments. Exp Brain Res 118:489-500.

Nuttin B, Cosyns P, Demeulemeester H, Gybels J, Meyerson B (1999) Electrical stimulation in anterior limbs of internal capsules in patients with obsessive-compulsive disorder. Lancet 354:1526.

Nuttin BJ, Gabriels LA, Cosyns PR, Meyerson BA, Andreewitch S, Sunaert SG, Maes AF, Dupont PJ, Gybels JM, Gielen F, Demeulemeester HG (2003) Long-term electrical capsular stimulation in patients with obsessivecompulsive disorder. Neurosurgery 52:1263-1272; discussion 1272-1264.

Ongur D, Price JL (2000) The organization of networks within the orbital and medial prefrontal cortex of rats, monkeys and humans. Cereb Cortex 10:206-219.

Perlmutter JS, Mink JW (2006) Deep brain stimulation. Annu Rev Neurosci 29:229-257.

Phillips CG (1959) Actions of antidromic pyramidal volleys on single Betz cells in the cat. Q J Exp Physiol Cogn Med Sci 44:1-25.

Pirot S, Jay TM, Glowinski J, Thierry AM (1994) Anatomical and electrophysiological evidence for an excitatory amino acid pathway from the thalamic mediodorsal nucleus to the prefrontal cortex in the rat. Eur J Neurosci 6:1225-1234.

Priori A, Ardolino G, Marceglia S, Mrakic-Sposta S, Locatelli M, Tamma F, Rossi L, Foffani G (2006) Low-frequency subthalamic oscillations increase after deep brain stimulation in Parkinson's disease. Brain Res Bull 71:149-154.

Rauch SL, Jenike MA, Alpert NM, Baer L, Breiter HC, Savage CR, Fischman AJ (1994) Regional cerebral blood flow measured during symptom provocation in obsessive-compulsive disorder using oxygen 15-labeled carbon dioxide and positron emission tomography. Arch Gen Psychiatry 51:62-70.

Rehncrona S, Johnels B, Widner H, Tornqvist AL, Hariz M, Sydow O (2003) Long-term efficacy of thalamic deep brain stimulation for tremor: double-blind assessments. Mov Disord 18:163-170.

Rodriguez-Oroz MC, Obeso JA, Lang AE, Houeto JL, Pollak P, Rehncrona S, Kulisevsky J, Albanese A, Volkmann J, Hariz MI, Quinn NP, Speelman JD, Guridi J, Zamarbide I, Gironell A, Molet J, Pascual-Sedano B, Pidoux B, Bonnet AM, Agid Y, et al. (2005) Bilateral deep brain stimulation in Parkinson's disease: a multicentre study with 4 years follow-up. Brain 128:2240-2249.

Sanchez-Vives MV, McCormick DA (2000) Cellular and network mechanisms of rhythmic recurrent activity in neocortex. Nat Neurosci 3:1027-1034.

Schoenbaum G, Roesch MR, Stalnaker TA (2006) Orbitofrontal cortex, decision-making and drug addiction. Trends Neurosci 29:116-124.

Schwartz JM, Stoessel PW, Baxter Jr LR, Martin KM, Phelps ME (1996) Systematic changes in cerebral glucose metabolic rate after successful behavior modification treatment of obsessive-compulsive disorder. Arch Gen Psychiatry 53:109-113.

Shahed J, Poysky J, Kenney C, Simpson R, Jankovic J (2007) GPi deep brain stimulation for Tourette syndrome improves tics and psychiatric comorbidities. Neurology 68:159-160.

Shu Y, Hasenstaub A, McCormick DA (2003) Turning on and off recurrent balanced cortical activity. Nature 423:288-293.

Stefanis C, Jasper H (1964) Recurrent collateral inhibition in pyramidal tract neurons. J Neurophysiol 27:855-877.

Steriade M, Nunez A, Amzica F (1993) A novel slow ( $<1 \mathrm{~Hz}$ ) oscillation of neocortical neurons in vivo: depolarizing and hyperpolarizing components. J Neurosci 13:3252-3265.

Sturm V, Lenartz D, Koulousakis A, Treuer H, Herholz K, Klein JC, Klosterkotter J (2003) The nucleus accumbens: a target for deep brain stimulation in obsessive-compulsive- and anxiety-disorders. J Chem Neuroanat 26:293-299.

Swedo SE, Schapiro MB, Grady CL, Cheslow DL, Leonard HL, Kumar A, Friedland R, Rapoport SI, Rapoport JL (1989) Cerebral glucose metabolism in childhood-onset obsessive-compulsive disorder. Arch Gen Psychiatry 46:518-523.

Swedo SE, Pietrini P, Leonard HL, Schapiro MB, Rettew DC, Goldberger EL, Rapoport SI, Rapoport JL, Grady CL (1992) Cerebral glucose metabolism in childhood-onset obsessive-compulsive disorder. Revisualization during pharmacotherapy. Arch Gen Psychiatry 49:690-694.

Tierney PL, Degenetais E, Thierry AM, Glowinski J, Gioanni Y (2004) Influence of the hippocampus on interneurons of the rat prefrontal cortex. Eur J Neurosci 20:514-524.

Tseng KY, Mallet N, Toreson KL, Le Moine C, Gonon F, O’Donnell P (2006) Excitatory response of prefrontal cortical fast-spiking interneurons to ventral tegmental area stimulation in vivo. Synapse 59:412-417.

Van Laere K, Nuttin B, Gabriels L, Dupont P, Rasmussen S, Greenberg BD, Cosyns P (2006) Metabolic imaging of anterior capsular stimulation in refractory obsessive-compulsive disorder: a key role for the subgenual anterior cingulate and ventral striatum. J Nucl Med 47:740-747.

Visser-Vandewalle V, Temel Y, Boon P, Vreeling F, Colle H, Hoogland G, Groenewegen HJ, van der Linden C (2003) Chronic bilateral thalamic stimulation: a new therapeutic approach in intractable Tourette syndrome. Report of three cases. J Neurosurg 99:1094-1100.

Vitek JL (2002) Mechanisms of deep brain stimulation: excitation or inhibition. Mov Disord 17 [Suppl 3]:S69-S72. 